\title{
Digital economy, the development ways of cryptocurrency
}

\author{
Oxana G. Ananova* \\ Don State Technical University, 344000 Rostov-on-Don, Russia
}

\begin{abstract}
The article is devoted to new directions of development of the digital economy. The analysis of technology development and cryptocurrency blokcheyn. Analyzed the problems and prospects of transition to digital economy technology.
\end{abstract}

\section{Introduction}

The term "digital economy" was first introduced to universal use by scientists from the University of Massachusetts, Nicholas Negroponte in 1995. Nicholas Negroponte used the term "digital economy" to more accurately explain the benefits of the new economy, which is closely related to the intensive development of information and communication technologies.

The Russian Information Society Development Strategy for 2017-2030 approved in Russia provides the following definition of the digital economy: "Digital economy is an economic activity in which the key factor in production is digital data, processing large volumes and using the results of analyzing them in comparison with traditional forms of management can significantly improve the efficiency of various types of production, technology, equipment, storage, sales, delivery goods and services." [1]

In other words, the digital economy is an activity directly related to the development of digital computer technology, which includes services for the provision of online services, and electronic payments, and online trading, and crowdfunding, and more. Usually, the main elements of the digital economy are e-commerce, Internet banking, electronic payments, Internet advertising, as well as Internet games [2-6].

The aim of this study is to clarify the characteristics of the digital economy, analyze the current state of the digital economy in the Russian Federation and determine the prospects for its development. The authors of the study set the following tasks, the solution of which is reflected in this article:

1. The study of the concept of "digital economy";

2. Bitcoin and blockchain;

3. Trends for further development.

\footnotetext{
*Corresponding author: o_ananova@mail.ru
} 


\section{Main part}

First of all, the high growth rates of interest in the digital economy and its implementation are associated with rapidly developing new information technologies. The explosive growth of social networks, the smartphone market, broadband Internet access, the development and improvement of artificial intelligence led to a rapid increase in the use of technology by consumers, and more than $40 \%$ of the world's population already has access to the World Wide Web. The growth in consumption of new technology products in the last 20 years of the 20th century has provoked the emergence of new opportunities in the market [3].

As a result of the active use of methods for analyzing large amounts of data, the concept of a digital economy has emerged. Having formulated the first definition of the term "digital economy" in 1995, Nicholas Negroponte identified the main shortcomings of the classical commodity economy and classic goods and compared them against the background of the advantages of the digital economy. Nicholas Negroponte highlighted the following advantages of the new economy:

- lack of physical weight of goods sold;

- low resource costs for the production of electronic goods;

- virtuality and instant movement of goods over the Internet.

Like any innovation, the development of the digital economy was accompanied by certain stages. The first stage in the development of the digital economy was the emergence and development of the World Wide Web. Despite the initial goal of creating the Internet, which was to create a decentralized system of communication between computers and used for the first time to send electronic messages, expanding the Internet was gaining more and more opportunities. And in 1994, the development of the Internet provoked the creation of the first online store. Jeff Bezos decided to open the first online store Amazon, which later became an e-commerce giant. In the same year, the American bank Stanford Federal Credit Union launched the world's first Internet banking system, which allows money transfers to others and make payments on loans. It was these events that triggered the transition of the digital economy to the next stage.

At the next stage, the massive development of the digital economy, the opening of new online stores, the improvement of Internet banking and the development of retail chains and banks led to the creation of a virtual world. Undoubtedly, the high growth rates and development of business entities in the digital economy are bound to have free access to the World Wide Web. The result of this stage of development of the digital economy was the widespread emergence of virtual banks, shops, and offices that lack physical representation.

The final stage in the development of the digital economy was the emergence of electronic money and an increase in sales of various electronic goods. As a result, the digital economy got its monetary system different from the real economy.

The need to study the nature of the nature of electronic money (cryptocurrency) will allow a more detailed understanding of the phenomenon of the digital economy.

Cryptocurrency is one of the components of the digital economy. The first bitokin center was founded in New York. Bitcoin is the world's first decentralized payment system that uses the same name unit of account and the same name data transfer protocol, developed in 2009 by a group of programmers under the pseudonym Satoshi Nakamoto.

If you more thoroughly understand the technology of Bitcoin and other cryptocurrencies, then the first thing you need to understand the technology of the blockchain, it is they who should become the basis of the new digital economy. Bitcoins exist only as entries in the blockchain.

Blockchain is a database that stores information about all transactions of system participants. The main and main feature of the blockchain is the use of mathematical calculation algorithms, which exclude errors inherent in the human factor [7]. A system is a 
voluntary network of connected computers. If you "own" Bitcoin, then you simply have the opportunity to transfer control over these records to someone else, fixing the fact of this transfer on the blockchain. Among the main advantages of using the blockchain are the following:

- data encryption;

- protection of information, excluding its falsification;

- clear definition and fixation of the time of the transaction, without the possibility of subsequent changes;

- low probability of distortion of information and making mistakes;

- real-time transaction control.

However, it is worth noting that the real-time mode used in Bitcoin payment systems is rather arbitrary, since the recording and recording of transactions takes place every 10 minutes.

Now the blockchain is gaining popularity in the business community, and the pace of global adoption is constantly increasing. For business, the main motivator of implementation is process optimization and overall savings. According to the calculations of the consulting company Accenture, the use of this technology reduces the cost of banks by an average of $30 \%$. The blockchain technology is most actively used in finance, and the main outsider of implementation is light industry and energy. In turn, in Russia, the blockchain is in demand in areas where it is necessary to ensure maximum transparency and protection, that is, in the state and banking sector.

Also, despite a number of advantages, we should not forget that this relatively "perfect" payment system has its own drawbacks that impede the widespread introduction and provision of them for business. The main disadvantage is associated with the system used to perform and record information during the implementation of transactions. The increase in transactions leads to an inevitable increase in the blockchain's "massiveness", therefore, an increase in the blockchain requires an increase in the capacity of hard disks, and the efficiency of transaction execution is reduced, which during peak loads leads to an inevitable decrease in operation in a given mode of operation. Bitcoin users have recently faced similar problems, when, due to the increased demand for this cryptocurrency, nearly two hundred thousand unconfirmed transactions "hung" for a long time. These and other facts require a sober and balanced analysis. Before finally entering the accounting practice, the blockchain technology must overcome the "childish" problems associated with the complexity of scaling and excessive resource dependence.

\section{Conclusion}

The study showed that, thanks to the blockchain technology, eight of the ten largest investment banks will be able to save from 8 to 12 billion dollars annually. The technology helps banks to move away from the fragmented database structure, available and accessible information, which will reduce the time and money spent on reconciling this information. Thus, although the Blockchain technology is still very young, its use is rapidly expanding. Many leading financial companies invest hundreds of millions of dollars in Blockchain technology. The new system penetrates our daily life deeply enough Platforms for technology-based business application development. Blocking can be performed only with the observance of copyright, tracking production processes or other goods for its compliance with the stated standards, not to mention absolutely all financial transactions. 


\section{References}

1. V.V. Pshenichnikov, A.V. Babkin, St. Petersburg State Polytechnical University Journal. Economics, 10 (1), 32 (2017) doi: 10.18721/JE.10103

2. P. L. Mashchenko, M. O. Pilipenko, Science, technology and education, 32, 61 (2017)

3. M. P. Voronov, V. P. Chasovskikh, Modern Problems of Science and Education, 9-1, 30 (2017)

4. M. Crosby, P. Pattanayak, S. Verma, V. Kalyanaraman, Applied Innovation, 2, 6 (2016)

5. J. Sun, J. Yan, K. Z. K. Zhang, Financial Innovation, 2 (1), 26 (2016)

6. S. Raval, Decentralized Applications: Harnessing Bitcoin's Blockchain Technology (O'Reilly Media, Inc., 2016)

7. D.D. Burkal'tseva, A.S. Tyulin, Perspektivy nauki - 2016: mater. III Mezhdunar. zaoch. Konkursa nauchno-issled. rabot, 41 (2016) 